\title{
Postharvest fruit density as an indicator of dry matter and ripened soluble solids of kiwifruit
}

\author{
Robert B. Jordan ${ }^{\mathrm{a}, *}$, Eric F. Walton ${ }^{\mathrm{b}}$, Karin U. Klages ${ }^{\mathrm{b}}$, Richard J. Seelye ${ }^{\mathrm{a}}$ \\ a Technology Development Group, HortResearch, Private Bag 3123, Hamilton, New Zealand \\ ${ }^{\mathrm{b}}$ Plant Development Group, HortResearch, Private Bag 3123, Hamilton, New Zealand
}

Received 18 January 2000; accepted 23 May 2000

\begin{abstract}
The density of unripe kiwifruit (Actinidia deliciosa (A. Chev.) C.F. Liang et A.R. Ferguson cv. Hayward) early in storage was investigated as a means of determining the current fruit dry matter (DM) and total sugar-plus-starch concentrations, and of predicting DM and soluble solid concentrations later when the fruit had ripened. To investigate the robustness of the density relationships with DM and ripe fruit soluble solids, measurements were made on fruit collected in a survey involving 208 New Zealand orchards ( $\sim 10 \%$ of the total) across the normal harvest season (early May-early June). Density measured on unripe fruit early in storage correlated with both DM measured at the same time $\left(r^{2}=82.6 \%\right.$; S.E. $=0.68 \%$ fresh weight $\left.(\mathrm{FW})\right)$, and with SSC measured after ripening $\left(r^{2}=85.1 \%\right.$; S.E. $=0.57 \% \mathrm{FW}$ ). As fruit taste is related to sugar concentration, and sugars make up the bulk of the soluble solids in fruit, this suggests potential for automated bulk taste sorting of kiwifruit at harvest by floating off low DM fruit in prepared salt solutions. To investigate the reasons for the relationship between density and other fruit measurements, fruit composition was analysed. Fruit taken from storage 2 weeks after harvest were graded non-destructively by density into four distinct dry matter groups, each containing eight fruit (four pairs matched by density). Paired fruit were separated and analysed for DM, soluble solids, starch and sugars (sucrose, glucose and fructose), one fruit immediately and the other after ripening. Equations relating density to both DM and ripe fruit soluble solids in the composition trial had similar parameter values to those of the survey trial and gave S.E. of prediction of about $0.3 \%$ FW. DM levels were about 3.2\% FW above the sum of soluble solids and starch concentrations in both ripe and unripe fruit, a difference largely independent of DM concentration. Starch lost during ripening was accounted for by the increase in the glucose and fructose sugar pools, and these two sugars had near equal concentrations at each DM level. Sucrose and minor sugar levels were independent of DM and ripeness. (C) 2000 Elsevier Science B.V. All rights reserved.
\end{abstract}

Keywords: Kiwifruit; Composition; Carbohydrates; Density; Ripening; Maturity

\section{Introduction}

* Corresponding author. Tel:: +64-858-4748; fax: + 64-78584705 .

Density has long been used as an estimator of

E-mail address: jordanb@hort.cri.nz (R.B. Jordan). dry matter (DM), soluble solids, maturity, quality 
and defects in fruit and vegetables, and consequently, has been used to grade these products (Smith and Nash, 1940; Nelson et al., 1963; Gutterman, 1976; Zaltzman et al., 1987; Abbott et al., 1997). In kiwifruit, density measured at harvest is positively correlated with both DM, and soluble solids concentration (SSC) of ripe fruit (Asami et al., 1988; Richardson et al., 1997). Further, Crisosto (1992) suggested that DM measurements made at any time after harvest provide a reliable predictor of ripe fruit soluble solids content and hence fruit quality. Relationships have also been shown between consumer acceptability and both the DM (Scott et al., 1986), and the ripe SSC (MacRae et al., 1989; Mitchell et al., 1992) of the fruit. In fact, DM, because of its relationship with ripe fruit $\mathrm{SSC}$, is now used as the target parameter for the near infra red (NIR) grading equipment currently under development (see Jordan et al., 1997; Kupferman, 1997). Density offers an alternative to NIR for assessing kiwifruit DM non-destructively in the laboratory, and in commercial grading operations.

There is a simple reason why fruit density can be used to assess the DM fraction of kiwifruit. Sugars and starch are the major components of kiwifruit DM (Beever and Hopkirk, 1990). Their densities are similar (1530 and $1590 \mathrm{~kg} / \mathrm{m}^{3}$, respectively; Lide, 1998), and are greater than that of water $\left(1000 \mathrm{~kg} / \mathrm{m}^{3}\right)$. Thus fruit density is higher for those with more solids. However, this relationship is affected by fruit intercellular air spaces which may exceed $3 \%$ of fruit volume (Hallet et al., 1992) and reduce the density proportionally (Wilson and Lindsay, 1969), but not to the point where the fruit float in water. Although gases are produced when fruit ripens, total gas volumes appear reasonably constant in fruit at similar points of their development/storage life (Jordan, unpublished data) and therefore do not affect the usefulness of the density/DM relationship.

At harvest, much of the carbohydrate in kiwifruit is starch, which on ripening is hydrolysed to sugars (Given, 1993), requiring laboratory methods to estimate potential sugar concentrations of fruit at harvest. Monitoring the changes in fruit composition during ripening is difficult to follow quantitatively because of the variation in individ- ual fruit DMs and ripening times, and because current laboratory methods are destructive. Nondestructive estimates of DM using density allow individual fruit with vastly different DMs to be followed during development and storage.

This study investigates the relationship between density and composition of kiwifruit across ranges of DM, and before and after ripening, both at a large scale using a broad survey to establish robustness, and at a laboratory scale to detail the mechanisms involved.

\section{Materials and methods}

\subsection{Survey trial}

Export quality kiwifruit (Actinidia deliciosa (A. Chev.) C.F. Liang et A.R. Ferguson cv. Hayward) were collected from 208 orchards selected at random from nine commercial pack-houses across New Zealand during the 1996 kiwifruit harvest (May 4-June 9). Throughout the season, fruit samples were taken automatically from the grader, removing one 36 count size $(\sim 100 \mathrm{~g})$ fruit from every 500-1000 graded until 72 fruit were collected from each orchard line. Fruit were packed into trays and immediately placed in cool storage until the end of the harvest season. In mid-June, fruits were transferred to the Ruakura Research Centre for analysis, which was completed by July 10 .

Fruit from each orchard were sorted separately into five density categories by flotation. After equilibration to room temperature, fruit were passed across a 1-m-long brush/spray unit to ensure wetness, minimising the effect of bubbles during flotation. They were placed in wire baskets, and lowered sequentially into four tanks $(900 \times 600 \times 700 \mathrm{~mm})$ containing magnesium sulphate solutions made up to different densities $\left(1024.6,1031.4,1038.2\right.$, and $\left.1045.1 \mathrm{~kg} / \mathrm{m}^{3}\right)$, and a wetting agent. Fruit that floated in the lowest density tank were retained, and those that sank were moved to the next highest density tank. This process was repeated to generate five categories of fruit from each sample, although many orchards 
only yielded fruit in four of the five categories. One fruit was then taken from each category from each orchard for analysis without ripening (an 812 fruit sub-sample), and a second for analysis after ripening (789 fruit; note, some fruit were lost to rots and damage).

On the following day, both sub-samples were measured individually for density by displacement, applying appropriate corrections for apparatus volume, fruit and water temperatures, and the weight of water retained on wet fruit. The non-ripened fruit were also analysed at that time for DM by removing two 5-mm slices from the equatorial region, weighing them together, oven-drying at $65^{\circ} \mathrm{C}$ until constant weight, and expressing the result as a percentage of fresh weight $(\% \mathrm{FW})$.

Fruit to be ripened were held at $\sim 25^{\circ} \mathrm{C}$ for 2-7 days until each reached eating firmness (approximately $8 \mathrm{~N}$, the end point determined by feel and checked using a penetrometer with a 7.9-mm plunger on auxiliary fruit). As each fruit became ripe, it was returned to storage at $0^{\circ} \mathrm{C}$, and when all were ripe, analysis for DM and SSC started within $24 \mathrm{~h}$. Fruit were equilibrated to room temperature before analysis. Slices (15$\mathrm{mm}$ ) were removed from each end of the fruit and juice squeezed from them separately onto a digital refractometer (Atago $^{\mathrm{TM}}$, Japan) calibrated in ${ }^{\circ}$ Brix, and the means of the two ends were reported as SSC expressed as ${ }^{\circ}$ Brix, (grams of sucrose equivalent per $100 \mathrm{~g}$ of juice). DM analyses, as described above, were also performed on these fruit.

\subsection{Composition trial}

Kiwifruit were harvested from two Bay of Plenty orchards in New Zealand during late May 1997, graded and packed as for export and held in cool-storage $\left(0^{\circ} \mathrm{C}\right)$ for approximately 2 weeks. One tray of fruit of average size (36 count, $\sim 100 \mathrm{~g}$ each) was randomly selected from each orchard line, and the fruit individually assessed for density as above. Fruit from each orchard were then ranked by density. Sixteen pairs of fruit with closely matched densities were selected, four pairs near each of the nomi- nal densities 1031, 1037, 1044 and $1050 \mathrm{~kg} / \mathrm{m}^{3}$. This provided a sample of matched pairs of fruit representing the typical range of densities of the New Zealand kiwifruit crop. It is notable that the eight pairs with the lowest densities came from one orchard and the remainder from the other. The pairs of fruit were then separated into two sets for composition analysis, one set immediately, and the other after ripening. This permitted direct comparison of the composition of pre- and post-ripened fruit with equal densities and therefore similar DMs.

The 'unripened' fruit sample was stored at $0^{\circ} \mathrm{C}$ overnight and analysed the following day while the 'ripened' sample was ripened as above prior to analysis. All fruit were individually analysed for SSC and DM as described above. SSC readings were completed rapidly to eliminate errors from any starch particles settling on the sensor plate (checks on this were made with repeated readings on duplicate fruit). The remainder of each fruit was cut into 2-3 $\mathrm{mm}$ slices, weighed, frozen in liquid nitrogen and stored at $-20^{\circ} \mathrm{C}$. Later, these samples were lyophilised, ground and analysed for sugars and starch, expressed as \% FW (Klages et al., 1998).

$\mathrm{SSC}$, as determined by refractometer, is a measure of the soluble material in the juice. Consequently, it must be adjusted to a whole fruit basis to allow comparison with other fruit constituent measurements (see AOAC method 932.12; Anon, 1995). Using DM and SSC, soluble solids in whole fruit (SSF) can be calculated as a percentage of $\mathrm{FW}$, using:

$\mathrm{SSF}(\% \mathrm{FW})=\frac{\mathrm{SSC}(100-\mathrm{DM})}{(100-\mathrm{SSC})}$

\section{Results and discussion}

\subsection{Survey trial}

The regression of initial density against DM from the 812 unripened survey fruit (Fig. 1) is

$\mathrm{DM}(\% \quad \mathrm{FW})=8.4[ \pm 0.13]+$

$$
0.210[ \pm 0.004] \times(\text { Density }-1000)
$$


$\left(r^{2}=82.6 \%\right.$; S.E.M. DM estimate $=0.68 \%$ FW $)$. Parameter S.E. are shown here and subsequently inside square brackets. The independent variable 'density -1000 ' is used because water (density = $1000 \mathrm{~kg} / \mathrm{m}^{3}$ ) is the notional zero point of the DM scale. It is worth noting that the slope term (0.210) is dependent on the density of the DM of the fruit solids, and the offset (8.4) depends on both DM density and the amount of gas present (Wilson and Lindsay, 1969). If the volume of air and gases in the fruit were more variable, we would expect the $r^{2}$ of the above regression to be smaller.

The regression of initial density against ripe fruit SSC (Fig. 2) from 789 ripened survey fruit is

Ripe fruit SSC $\left({ }^{\circ}\right.$ Brix $)=5.7[ \pm 0.11]+$

$$
0.189[ \pm 0.003] \times(\text { Density }-1000)
$$

$\left(r^{2}=85.1 \%\right.$; S.E.M. SSC estimate $=0.57^{\circ}$ Brix $)$. Because DM was not measured for this sample, it was not possible to calculate the SSF values.

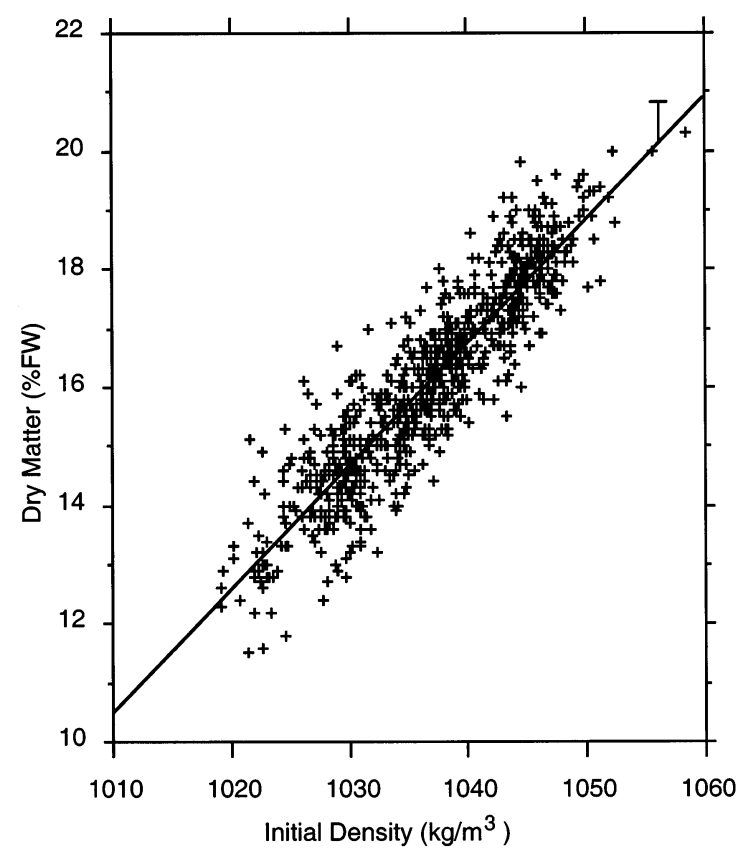

Fig. 1. DM vs. initial density and associated regression line of individual kiwifruit sub-sampled from 208 New Zealand orchards. Error bar indicates one S.E. of the fit of the data to the line.

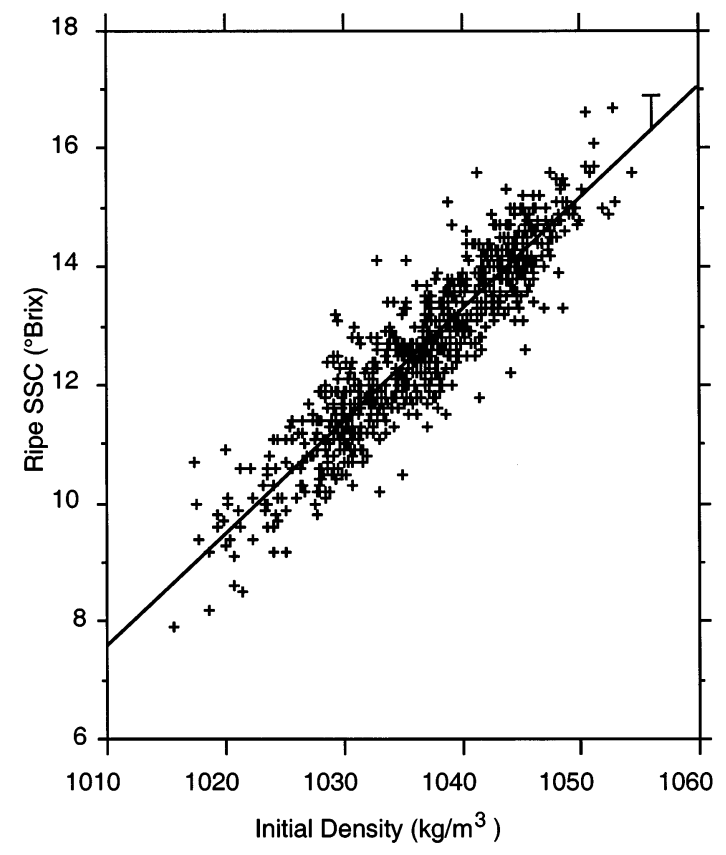

Fig. 2. Ripe fruit SSC vs. initial density and associated regression line of individual kiwifruit sub-sampled from 208 New Zealand orchards. Error bar indicates one S.E. of the fit of the data to the line.

Considering the extensive nature of the survey, both DM and SSC relationships have high $r^{2}$ values, and S.E. reported are likely to be smaller in absolute magnitude than the level that a human can differentiate.

\subsection{Composition trial}

The means and S.E. of composition measurements of the four fruit in each density category and ripeness group are shown in Table 1.

\subsubsection{Density and dry matter}

Density values for the fruit (Table 1) covered the full range of results reported by Asami et al. (1988), and DMs extended from 14-19.5\% FW (Fig. 3), representing the typical range for 'Hayward' kiwifruit (Beever and Hopkirk, 1990). Good matches of DM concentrations between the ripened/unripened pairs (linked symbols in Fig. 3) were found (S.E.M. $<0.25 \% \mathrm{FW}$; mean difference 
between pairs $<0.1 \% \mathrm{FW}$ ). This pair matching and the DM range produced, justify the use of density as a selection criterion and created a unique data set with which to explore composition changes with ripening. Results are clearly grouped within each of the four nominal density categories (Fig. 3), and a trend is evident both between and within the two orchards (orchard 1 below and orchard 2 above the $1042 \mathrm{~kg} / \mathrm{m}^{3}$ point, respectively). Similar groupings appeared in each of the other measurements made and showed no suggestion of difficulties caused by taking the fruit from different orchards. There was no significant difference between the DMs of ripe and unripe groups.

The regression line for DM against initial density of all fruit shown in Fig. 3 is
$\mathrm{DM}(\% \mathrm{FW})=8.2[ \pm 0.3]+$

$$
0.209[ \pm 0.008] \times(\text { Density }-1000)
$$

$\left(r^{2}=96.2 \%\right.$; S.E.M. $\left.=0.3 \% \mathrm{FW}\right)$. This strong correlation between initial density and DM measurements has been reported before (Richardson et al., 1997), however, their coefficients were different, tending to have lower slopes (0.192), and higher offsets (10.23) perhaps due to the fact that their measurements were made at normal harvest time.

Corresponding values for DM obtained by the oven method and for the lyophilised samples (Table 1) matched to $0.6 \% \mathrm{FW}$ on average, with oven DMs being slightly lower. Only two individual oven DMs were more than $1.2 \% \mathrm{FW}$ lower than the lyophilised DMs.

Table 1

Mean and S.E.M. (in brackets) of measurements made on four fruit in each of four density categories of both unripe and ripe fruit ${ }^{\mathrm{a}}$

\begin{tabular}{|c|c|c|c|c|}
\hline & \multicolumn{4}{|c|}{ Nominal density group } \\
\hline & $1031\left(\mathrm{~kg} / \mathrm{m}^{3}\right)$ & $1037\left(\mathrm{~kg} / \mathrm{m}^{3}\right)$ & $1044\left(\mathrm{~kg} / \mathrm{m}^{3}\right)$ & $1050\left(\mathrm{~kg} / \mathrm{m}^{3}\right)$ \\
\hline \multicolumn{5}{|l|}{ Unripe fruit } \\
\hline Initial density $\left(\mathrm{kg} / \mathrm{m}^{3}\right)$ & $1031.1(0.30)$ & $1036.8(0.43)$ & $1044.2(0.42)$ & $1049.8(0.68)$ \\
\hline Initial SSC ( ${ }^{\circ}$ Brix $)$ & $10.7(0.28)$ & $11.2(0.28)$ & $11.3(0.21)$ & $12.3(0.43)$ \\
\hline Lyophilised DM (\% FW) & $15.3(0.20)$ & $16.9(0.22)$ & $18.0(0.35)$ & $19.7(0.19)$ \\
\hline Fructose $(\% \mathrm{FW})$ & $2.3(0.12)$ & $2.5(0.13)$ & $2.6(0.13)$ & $2.8(0.18)$ \\
\hline Glucose $(\% \mathrm{FW})$ & $2.1(0.12)$ & $2.2(0.11)$ & $2.2(0.17)$ & $2.4(0.20)$ \\
\hline Sucrose $(\% \mathrm{FW})$ & $1.4(0.07)$ & $1.6(0.07)$ & $1.3(0.05)$ & $1.5(0.08)$ \\
\hline Minor sugars $(\% \mathrm{FW})$ & $0.14(<.01)$ & $0.14(<.01)$ & $0.12(<.01)$ & $0.13(<.01)$ \\
\hline Initial density $\left(\mathrm{kg} / \mathrm{m}^{3}\right)$ & $1031.1(0.32)$ & $1036.5(0.42)$ & $1044.1(0.45)$ & $1049.9(0.80)$ \\
\hline Ripe density $\left(\mathrm{kg} / \mathrm{m}^{3}\right)$ & $1040.4(0.51)$ & $1045.9(1.28)$ & $1052.5(0.99)$ & $1058.3(1.13)$ \\
\hline Ripe SSC ( ${ }^{\circ}$ Brix) & $12.0(0.15)$ & $13.3(0.18)$ & $14.5(0.21)$ & $15.9(0.17)$ \\
\hline Ripe SSF (\% FW) & $11.7(0.15)$ & $12.9(0.18)$ & $14.0(0.23)$ & $15.4(0.17)$ \\
\hline Ripe DM ( $\%$ FW) & $14.5(0.16)$ & $16.0(0.19)$ & $17.4(0.07)$ & $18.7(0.16)$ \\
\hline Lyophilised DM (\% FW) & $15.0(0.10)$ & $16.1(0.25)$ & $17.9(0.06)$ & $19.2(0.20)$ \\
\hline Fructose $(\% \mathrm{FW})$ & $2.9(0.07)$ & $3.3(0.06)$ & $3.7(0.07)$ & $4.0(0.06)$ \\
\hline Glucose $(\% \mathrm{FW})$ & $2.7(0.11)$ & $3.2(0.10)$ & $3.7(0.03)$ & $4.0(0.05)$ \\
\hline Sucrose $(\% \mathrm{FW})$ & $1.3(0.04)$ & $1.6(0.06)$ & $1.6(0.05)$ & $1.9(0.07)$ \\
\hline Minor sugars $(\% \mathrm{FW})$ & $0.19(0.04)$ & $0.24(0.03)$ & $0.14(<.01)$ & $0.16(<.01)$ \\
\hline Starch $(\% \mathrm{FW})$ & $0.02(0.01)$ & $0.02(<.01)$ & $0.01(<.01)$ & $0.04(0.01)$ \\
\hline
\end{tabular}

${ }^{\text {a }} \mathrm{FW}$, fresh weight; and starch* is the starch concentration adjusted by $11 \%$ to reflect the amount of sugar it will produce following hydration. 


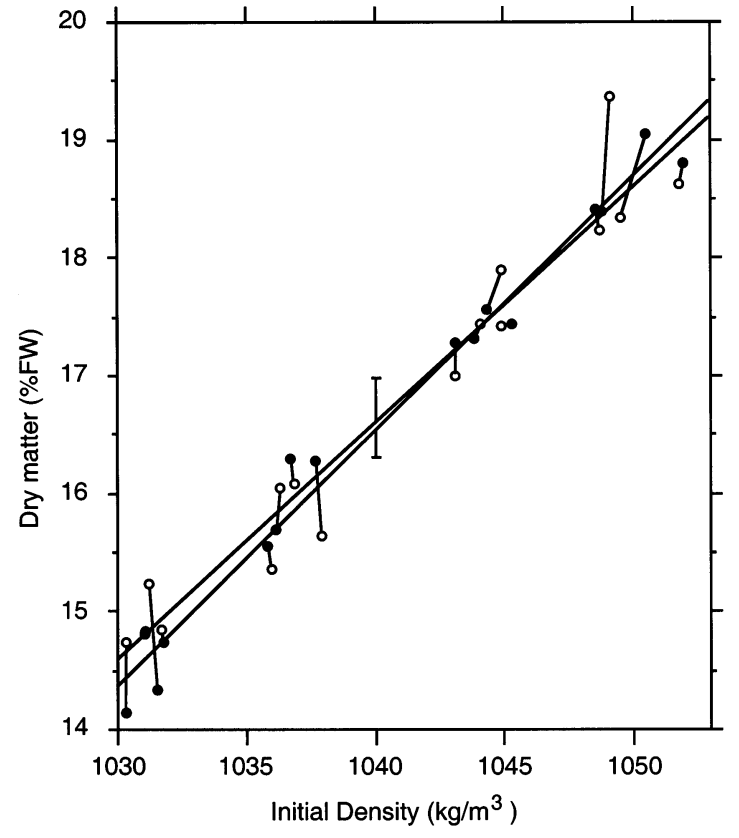

Fig. 3. DM of kiwifruit before $(\bigcirc)$ and after $(\bullet)$ ripening, plotted against initial density and showing the respective regression lines. Orchard 1 comprises the lower 16 data points. The S.E. of the data about the regression lines is shown as a bar at the mean density, and paired fruit are shown linked.

\subsubsection{Soluble solids}

The soluble solid concentrations of the ripe fruit were not dissimilar to the ranges of Beever and Hopkirk (1990), Paterson et al. (1991). SSC measurements of unripened fruit (mean, $11.4^{\circ}$ Brix) were above normal harvest values (typically fruit arrive at the pack house with mean SSCs between 6.5 and $10.5^{\circ}$ Brix) and comparison with the fully ripened figures above (mean, $13.9^{\circ}$ Brix) indicated that starch hydrolysis was already well underway. It was noted that fruit with higher density and DM tended to have higher SSC values. However, these fruit also had correspondingly more starch showing that starch conversion was proportionately less advanced.

The regression relationship between initial density and ripe fruit soluble solids expressed as $\%$ FW and including S.E. of the estimates is
Ripe fruit SSF $(\% \mathrm{FW})=5.9[ \pm 0.47]+$

$$
0.188[ \pm 0.011] \times(\text { Density }-1000)
$$

$r^{2}=95.0 \%$; S.E.M. $=0.33 \% \mathrm{FW}$ ).

Because ripe and unripe DM levels were matched (see Fig. 3), the potential soluble solids levels of ripened and unripened fruit should not be different. Although the data contributing to Eq. (5) do not extend across the complete ripening regime from normal harvest to full ripeness, our own studies (Jordan and Seelye, unpublished data) and that of Richardson et al. (1997) provide support for this relationship holding for all kiwifruit regardless of ripeness status. Initial density thus provides a means to non-destructively estimate the soluble solid levels of ripe kiwifruit. Ripe fruit SSC can also be estimated from initial density using the following regression

Ripe fruit SSC $\left({ }^{\circ}\right.$ Brix $)=5.9[ \pm 0.43]+$

$$
0.198[ \pm 0.010] \times(\text { Density }-1000)
$$

$\left(r^{2}=96.2 \%\right.$; S.E.M. $\left.=0.30 \% \mathrm{FW}\right)$. This relationship is similar to that reported by Asami et al. (1988) and Richardson et al. (1997) who gave slopes of 0.171 and 0.165 (cf our 0.198) and offsets of 7.89 and 7.47 (cf our 5.9), respectively. It is noteworthy that their relationships pertain to fruit analysed closer to harvest, and, as noted earlier, show lower slopes and higher offsets.

\subsubsection{Starch}

Starch contents of ripened fruit were low in all cases $(<0.05 \% \mathrm{FW})$ and contributed little to total carbohydrate. Concentrations in unripe fruit ranged from 1 to $4 \% \mathrm{FW}$ and were higher in high density fruit. Starch contents were lower than those typical of fruit at harvest (about 7\% FW, e.g. Fuke and Matsuoka, 1982; Walton and de Jong, 1990; Richardson et al., 1997).

By adding the concentrations of starch to soluble solids for each unripe fruit, an estimate of the potential soluble solids levels in ripe fruit can be made. To allow comparison with the sugars, the starch mass has been scaled up by $11 \%$ (labelled starch*) to account for the higher resultant sugar mass following hydrolysis. 
A comparison between ripe and unripe SSF-plus-starch* (Figs. 4 and 5) shows regression lines matching to better than $0.4 \% \mathrm{FW}$ at all densities, consistent with starch being hydrolysed to sugars on ripening.

\subsubsection{Sugars}

Results for ripe fruit sugars (Table 1) are typical of those of Beever and Hopkirk (1990), albeit at the low end of or lower than their ranges, and fit comfortably inside the ranges of Paterson et al. (1991) except for our highest sucrose value. Walton and de Jong (1990) report totals of sugars plus starch that are similar, although the relative fractions of their components differ from ours consistent with the later stage of ripeness of our fruit.

The major sugars measured had the following concentration ranking, fructose, glucose and sucrose. Minor sugars (myo-inositol, plus a sugar that co-eluted with galactose) were also present in

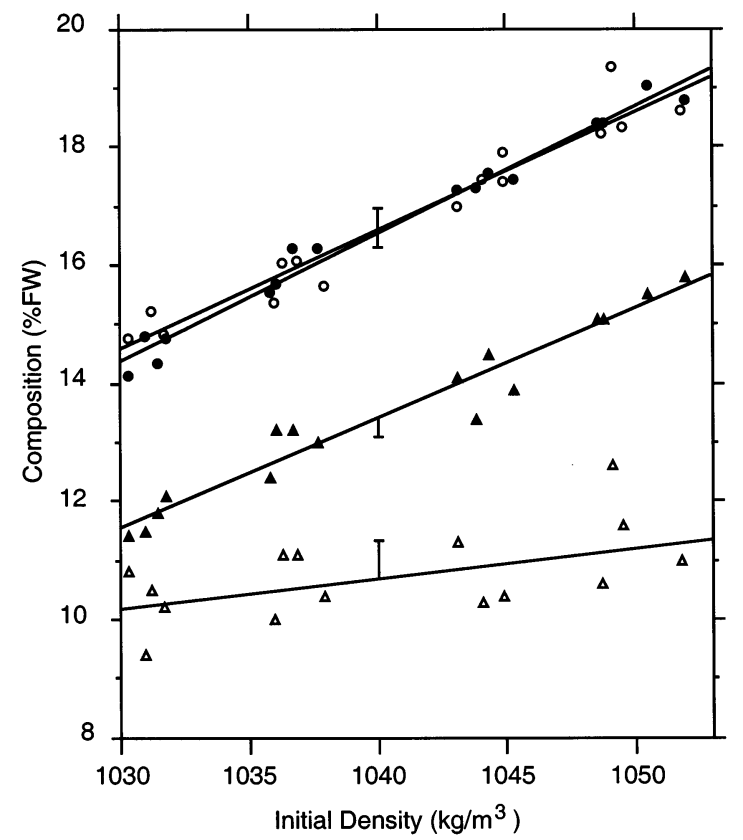

Fig. 4. DM (circles) and soluble solids (triangles) concentrations (expressed as \% FW) for ripened (closed symbols) and unripened (open symbols) kiwifruit and corresponding regression lines. Error bars show one S.E. of the fit to the regression lines, and the steeper DM line corresponds to the ripe fruit.

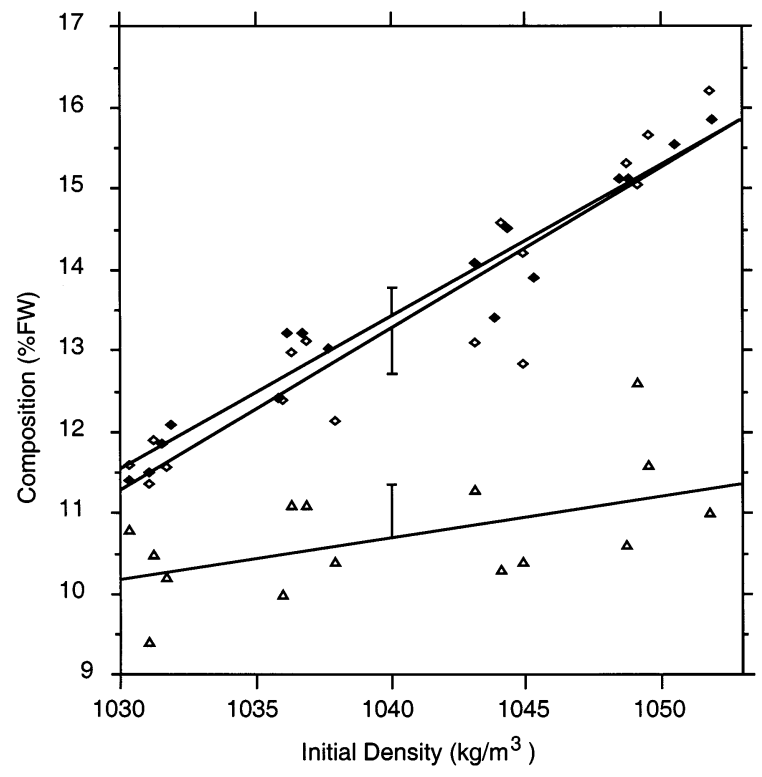

Fig. 5. Ripened (closed diamonds) and unripened (open diamonds) fruit soluble solids plus starch* (starch scaled by $11 \%$ ), and unripened fruit soluble solids (triangles) concentrations of kiwifruit plotted against their initial density with corresponding regression lines. Error bars show one S.E. of the fit to the regression lines and the steepest line is the unripe SSF + starch*.

low concentrations $(0.17$ and $<0.08 \% \mathrm{FW}$, respectively) and were grouped together in this study. By plotting sugars cumulatively, an illustration of fruit composition and the way it changes with increased density is provided (Fig. 6).

Total carbohydrates in both graphs (the top lines in Fig. 6) increased with density, and were similar in ripe and unripe groups, as planned by matching the original fruit pairs. Sucrose and minor sugars were largely constant regardless of ripeness-state or DM. While glucose and fructose in unripened fruit did not increase significantly with density, both showed significant trends with density in the ripened fruit. Furthermore, the net gains of glucose and fructose on ripening were nearly equal, and together, almost exactly matched the loss of starch. This follows a pattern found by Fuke and Matsuoka (1982), Sawanabori and Shimura (1990), and (until their fruit became over-ripe) MacRae et al. (1992), and is in agreement with glucose and fructose being sourced from starch. 


\subsubsection{Other soluble components}

The refractometer-based SSF (SSC as \% FW) measurement, and the chemically determined sugars (see Fig. 7) show an SSF that is greater than the sum of sugars by $4 \% \mathrm{FW}$, increasing to $5.5 \%$ FW in the ripened high density fruit. SSF would include the three fruit acids citric, quinic and malic which were not measured in these experiments and which are typically $1.0-1.6 \% \mathrm{FW}$ in total (Beever and Hopkirk, 1990; Walton and de Jong, 1990), although as high as $2.9 \%$ FW (Paterson et al., 1991). This leaves 2.4-3.9\% FW (cf. Beever and Hopkirk, 1990), or 1.1-2.6\% FW (cf. Paterson et al., 1991), of the SSF readings unidentified. This discrepancy, which is also apparent in the data of Fuke and Matsuoka (1982), may be due to the presence of another soluble component that we have not measured (e.g. potassium, nitrate or soluble pectins; see Beever and Hopkirk, 1990). Alternatively, less than the total carbohydrate was recovered from the fruit samples, resulting in a slight underestimate by our internal standards adjustments.

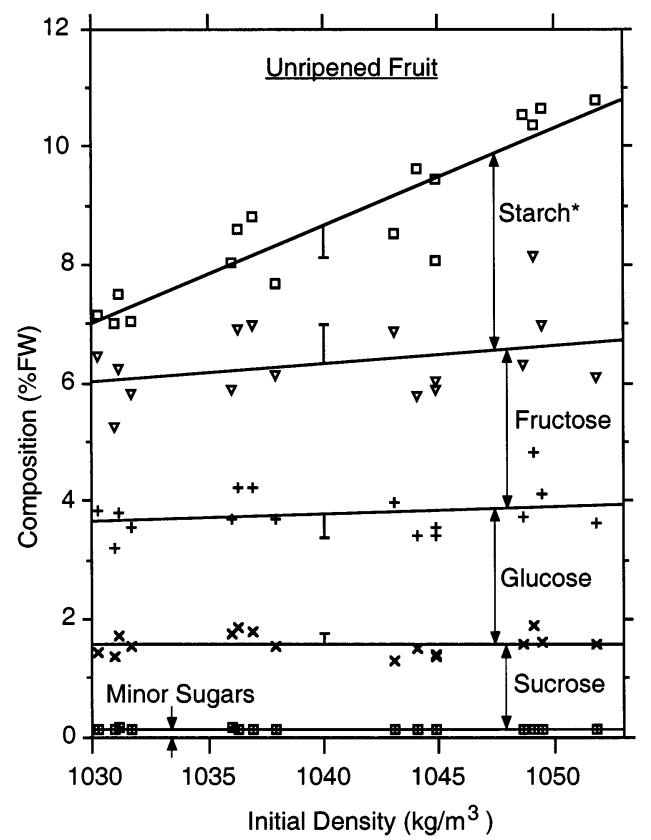

\subsubsection{Other insoluble components}

For ripened fruit, mean measurements of SSFplus-starch* over the density/ripeness groups were consistently lower than DM by $2.8-3.4 \%$ FW (see Table 1), while in the unripened fruit, this difference was $3.1-3.7 \% \mathrm{FW}$. These differences are also apparent by inspecting Figs. 4 and 5 and represent 'the insoluble non-starch fraction' of the DM. This insoluble fraction increases only slightly with higher DM fruit, and would contain cell wall, seeds, skin, and minor insoluble components, and should not be affected by the sugar and starch levels of the fruit.

\subsection{Comparison of survey and composition trial results}

The regression lines obtained in the survey and composition trials when compared have very close parameters for initial density against both DM (cf. slope 0.210 vs. 0.209 and offset 8.4 vs. 8.2, respectively) and ripe fruit SSC (cf. slope 0.189 vs. 0.198 and offset 5.7 vs. 5.9, respectively). Consid-

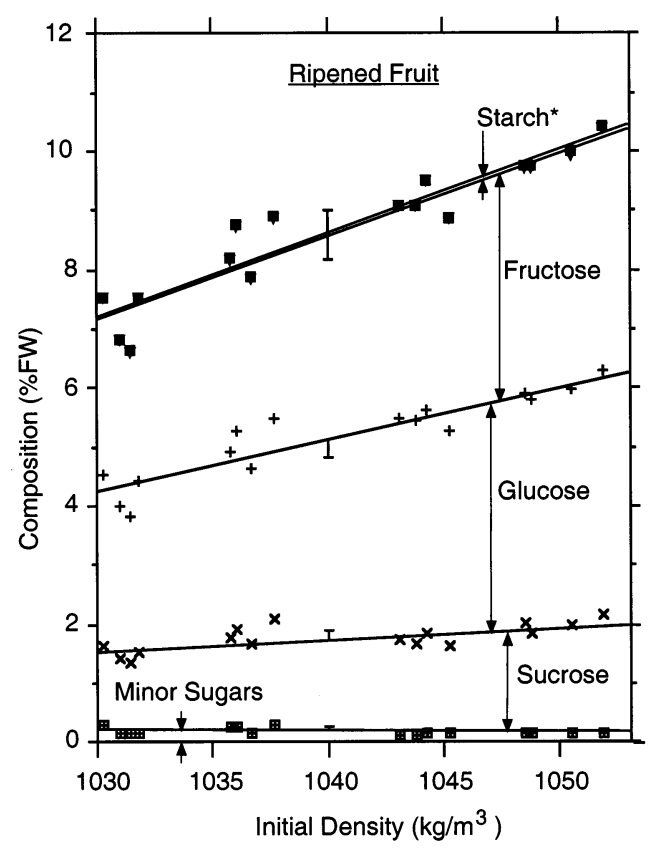

Fig. 6. Composition of kiwifruit plotted cumulatively in terms of sugars and starch* (starch scaled by $11 \%$ ) in unripened and ripened fruit showing regression lines. Error bars show one S.E. of the regression fit to cumulative carbohydrate measurements. Note: upper symbols in ripened fruit plot almost coincide due to the low starch* concentrations. 

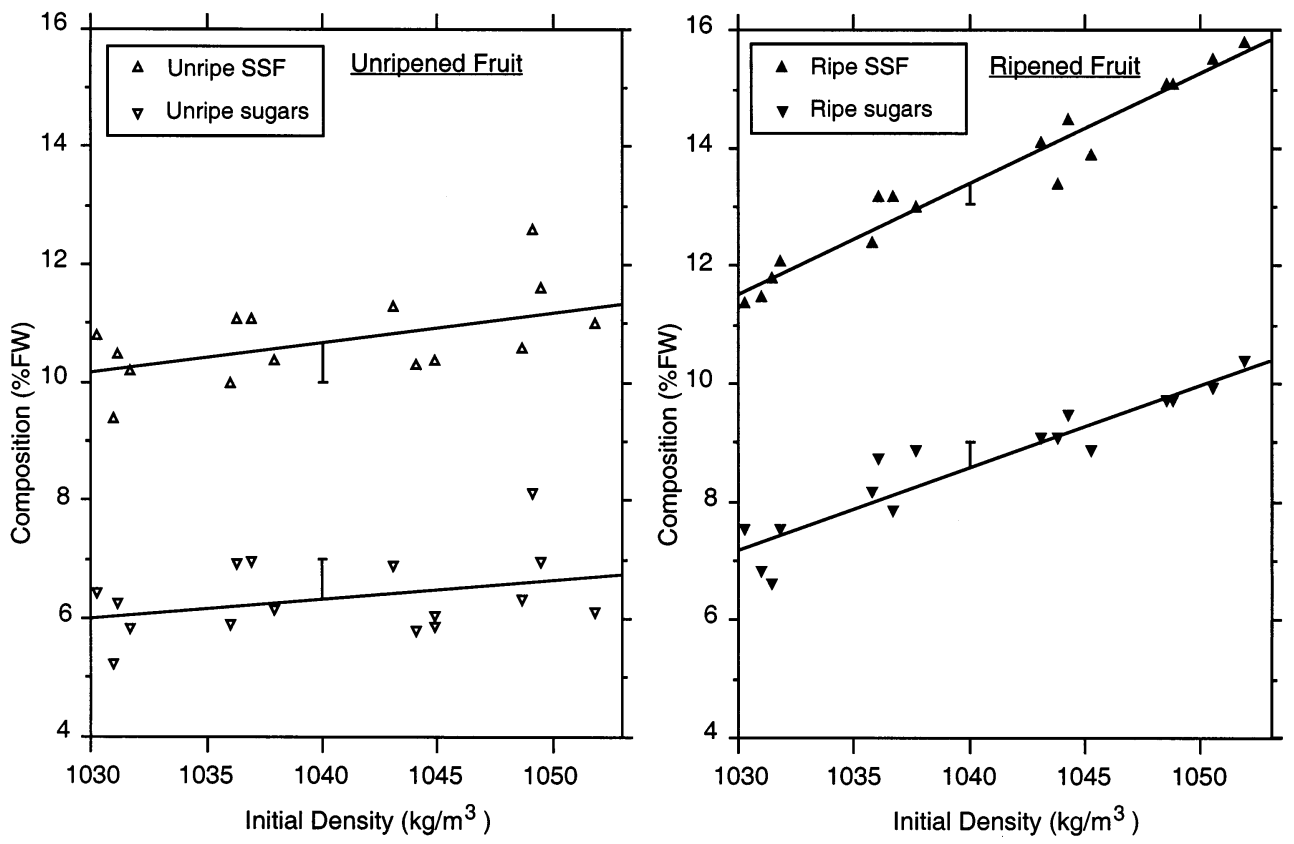

Fig. 7. Soluble solids in whole kiwifruit (SSF), and total sugar estimates for unripened and ripened data groups plotted against initial fruit density and showing regression lines. Error bars show one S.E. of the regression fit to the cumulative carbohydrate measurements.

ering the extensive nature of the sample taken in this survey, this confirms the robustness of the relationship in kiwifruit between initial density and the fruit DM and ripe fruit SSC.

It is worth noting that the sets of fruit in the survey and composition trials were stored for similar lengths of time prior to analysis and would have been at similar stages of ripeness. Had these trials been undertaken immediately after harvest, the regression parameters would have been different from those reported above, but would still have matched each other closely. This predicted change in regression parameters as fruit ripened might be due to a reduction of internal air spaces during early storage, but warrants further investigation.

\section{Conclusions}

Using density, we have investigated composition changes in kiwifruit over the full range of
DM levels experienced and have identified how these changes are affected by the DM levels. Fruit selected to have closely matching densities during early storage were shown to have closely matching DM, as well as total carbohydrate levels, both in early storage, and after ripening. Fruit with higher or lower density had correspondingly higher or lower DMs and SSCs when ripe, respectively. These experiments show that the increase during ripening of both soluble solids and of the sum of glucose and fructose concentrations in fruit of varying DM concentrations can be wholly accounted for by the loss of starch. Levels of residual insoluble components in the fruit (excluding starch) representing fruit structures are largely independent of the fruit DM. Even though the fruit studied came from two different orchards, there was no evidence that orchard differences affected the results.

There was a discrepancy between the total soluble fraction measured by chemical analyses 
and by refractometer which could not be accounted for from typical soluble acid concentrations reported in the literature, or by other identified sources of error.

Confirmation is provided that DM can be predicted from initial density measurements in laboratory experiments with S.E. as low as $0.3 \%$ FW and in a nation-wide survey to better than $0.7 \%$ FW. From the initial density measurements, and also from the DM, good estimates of final or ripe fruit soluble solids levels can be obtained. This suggests the utility of using fruit initial density to non-destructively sort kiwifruit on the basis of its DM and therefore its ultimate (ripe) SSC and thus its sugars. Such a result is evident in small-scale laboratory trials, and in large-scale industry wide surveys. This technology thus offers the potential to commercially sort kiwifruit into different eating qualities by allowing the fruit to float or sink in appropriate solutions adjusted to key densities.

\section{Acknowledgements}

We thank Helen Boldingh and Ian Waring for the carbohydrate analyses. This work was funded by the New Zealand Foundation for Research, Science and Technology (C06624). Fruit used in the survey trial were collected and analysed under funding from the New Zealand Kiwifruit Marketing Board (NZKMB 96155).

\section{References}

Abbott, J.A., Lu, R., Upchurch, B.L., Stroshine, R., 1997. Technologies for nondestructive quality evaluation of fruits and vegetables. Hort. Rev. 20, 2-120.

Anon, A., 1995. AOAC Method 932.12 solids (soluble) in fruit and fruit products. AOAC Official Methods Analysis 37 (1), 15.

Asami, I., Tanaka, Y., Aoki, M., 1988. Studies on the quality evaluation of kiwifruit (1) chemical composition and nondestructive quality evaluation method of kiwifruit. Res. Bull. Aichi Agric. Ctr. 20, 309-316.

Beever, D.J., Hopkirk, G., 1990. Fruit development and fruit physiology. In: Warrington, I.J., Weston, G.C. (Eds.),
Kiwifruit Science and Management. For the New Zealand Society of Horticultural Science. Ray Richards Publisher, pp. $97-126$.

Crisosto, C.H., 1992. Predicting high quality in kiwifruit. California Grower, September 1992.

Fuke, Y., Matsuoka, H., 1982. Changes in contents of sugars, starch, organic acids and free amino acids in kiwifruit during growth and after ripening. Nippon Shokuhin Kogyo Gakkaishi 29, 642-648.

Given, N.K., 1993. Kiwifruit. In: Seymour, G., Taylor, J., Tucker, G. (Eds.), Biochemistry of Fruit Ripening. Chapman \& Hall, London.

Gutterman, R.P., 1976. Mass flow density sorter for fruits and vegetables. In: J.J Gaffney (Compiler), Quality Detection in Foods. ASAE publication 1-76 in co-operation with the ASAE technical committee FE-74 on Food Handling.

Hallet, I.C., MacRae, E.A., Wegrzyn, T.F., 1992. Changes in kiwifruit cell wall ultra-structure and cell packing during postharvest ripening. Int. J. Plant Sci. 153, 49-60.

Jordan, R.B., Osborne, S.D., Künnemeyer, R., Seelye, R.J., 1997. Harvest time prediction of eating time properties of kiwifruit using NIR transmission. Proceedings of Sensors for Non-destructive Testing. International Conference, Orlando, FL, February 1997, p. 101.

Klages, K., Donnison, H., Boldingh, H., MacRae, E., 1998. myo-Inositol is the major sugar in Actinidia aguta during early fruit development. Aust. J. Plant Physiol. 25, 61-67.

Kupferman, E., 1997. Near infrared sorting for the Washington Apple Industry. Washington State Univ. Tree Fruit Postharvest J. 8, 4-9.

Lide, D.R. (Ed.), 1998. CRC Handbook of chemistry and physics, 79th ed, p. 1529.

MacRae, E.A., Bowen, J.H., Stec, M.G.H., 1989. Maturation of kiwifruit (Actinidia deliciosa cv Hayward) from two orchards: difference in composition of the tissue zones. J. Sci. Food Agric. 47, 401-416.

MacRae, E.A., Quick, W.P., Benker, C., Stitt, M., 1992. Carbohydrate metabolism during postharvest ripening in kiwifruit. Planta 188, 314-323.

Mitchell, F.G., Mayer, G., Biasi, W., 1992. Effect of harvest maturity on storage performance of 'Hayward' kiwifruit. Acta Hort. 297, 617-625.

Nelson, K.E., Baker, G.A., Winkler, A.J., Amerine, M.A., Richardson, H.B., Jones, F.R., 1963. Chemical and sensory variability in table grapes. Hilgardia 34, 1-42.

Paterson, V.J., MacRae, E.A., Young, H., 1991. Relationship between sensory properties and chemical composition of kiwifruit. J. Sci. Food Agric. 57, 235-251.

Richardson, A.C., MacAneney, K.J., Dawson, T.E., 1997. Carbohydrate dynamics in kiwifruit. J. Hort. Sci. 72, 907917.

Sawanabori, S., Shimura, I., 1990. Effects of growing location and season on fruit growth and development of 'Hayward' Kiwifruit. J. Jpn. Soc. Hort. Sci. 58 (4), 849-857.

Scott, K.J., Spraggon, S.A., McBride, R.L., 1986. Two new maturity tests for kiwifruit. CSIRO Food Res. Q. 46, $25-31$. 
Smith, O., Nash, L.B., 1940. Potato quality II. Relation of soil reaction irrigation and mineral nutrition to cooking quality. Proc. Am. Soc. Hort. Sci. 38, 507-512.

Walton, E.F., de Jong, T.M., 1990. Growth and compositional changes in kiwifruit berries from three Californian locations. Ann. Botany 66, 285-298.
Wilson, J.H., Lindsay, A.M., 1969. The relation between specific gravity and dry matter content of potato tubers. Am. Potato J. 46, 323-328.

Zaltzman, A., Verma, B.P., Schmilovitch, Z., 1987. Potential of quality sorting of fruits and vegetables using fluidized bed medium. Trans. ASAE 30, 823-831. 